\section{Claudia Miranda}

Universidade Federal do Estado do Rio de Janeiro - UNIRIO

Email: mirandaunirio@gmail.com

(D) https://orcid.org/0000-0001-6105-6356

\section{Helena Maria Marques Araújo}

Universidade Estadual do Rio de Janeiro - UERJ

Email: hmaraujo@ig.com.br

(D) https://orcid.org/0000-0003-2067-4187

\section{Memórias contra-hegemônicas e educação para as relações étnico-raciais: práticas decoloniais em contextos periféricos}

\section{Claudia Miranda Helena Maria Marques Araújo}

\section{Resumo}

Nossa perspectiva investigativa está influenciada pela possibilidade de análises dialéticas no plano da simultaneidade, e este trabalho parte de uma abordagem que reconhece coexistência epistemológica frente ao tema da história social, política e cultural de setores marginalizados como as populações afrodescendentes no Brasil e no Equador. Alinhadas ao pressuposto da decolonialidade do saber e da Educação para as relações étnico-raciais, tratamos das outras práxis educativas em contextos não formais de educação, dessa vez a partir do Museu da Maré e do Fundo Documental Afroandino. Ganham centralidade processos de reorientação epistemológica, como legados para os currículos praticados em contextos de invisibilização dos conhecimentos subalternizados. Defendemos outros "giros" e outras percepções sobre memória coletiva com base em uma perspectiva comparada, além de reconhecer a produção realizada como um modo outro de fazer da(s) memória(s), uma peça indispensável na luta social e política, assumindo contranarrativas e outras formas de insurgir.

Palavras-chave: Etnoeducação. Memórias contra-hegemônicas. Educação para as relações étnico-raciais. Museu da Maré. Fundo Documental Afro-andino. 


\begin{abstract}
Keywords:

Ethnoeducation. Counterhegemonic memories. Education for ethnic-racial relations. Museu da Maré. Afro Andean Documentary Fund..

Contra-hegemonic memories and education for ethnic-racial relations: decolonial practices in peripheral contexts

Abstract

Our research perspective is influenced by the possibility of dialectical analyzes in the plane of simultaneity and this work starts from an approach that recognizes epistemological coexistence in the face of the social, political and cultural history of marginalized sectors such as Afrodescendant populations in Brazil and Ecuador. Aligned with the presupposition of the decoloniality of knowledge and Education for ethnoracial relations, we deal with other educational praxis in non-formal contexts of education this time from the Museum of the tide and the AfroAndean Documentary Fund. Centrality gains processes of epistemological reorientation as legacy for the curricula practiced in contexts of invisibilization of subalternized knowledge. We advocate other "twists" and other perceptions about collective memory based on a comparative perspective, and recognize the production as another way of making memory (s), an indispensable piece in the social and political struggle, assuming against narratives and other forms of insurgency.
\end{abstract}

\section{Resumen}

Palabras clave: Etnoeducación. Memorias contrahegemónicas. Educación para las relaciones étnico-raciales. Museu da Maré. Fondo Documental Afro-andino.

La función de la escritura en la formación inicial de profesores: la tradición y la innovación en la enseñanza de lengua portuguesa

Nuestra perspectiva investigativa está influenciada por la posibilidad de análisis dialécticos en el plano de la simultaneidad y ese trabajo parte de un abordaje que reconoce coexistencia epistemológica frente al tema de la historia social, política y cultural de sectores marginados como las poblaciones afrodescendientes en Brasil y en el Ecuador. Alineadas al presupuesto de la decolonialidad del saber y de la Educación para las relaciones étnicas, tratamos de las otras praxis educativas en contextos no formales de educación esta vez a partir del Museo de la marea y del Fondo Documental Afro andino. Se gana centrales procesos de reorientación epistemológica como legado para los currículos practicados en contextos de invisibilización de los conocimientos subalternizados. Defendemos otros "giros" y otras percepciones sobre memoria colectiva basándose en una perspectiva comparada además de reconocer la producción realizada como un modo otro de hacer de la memoria (s), una pieza indispensable en la lucha social y política, asumiendo contra narrativas y otras formas de insurgir. 


\section{Introdução}

Os projetos de Educação com jovens em situação de pobreza extrema fazem parte de nosso horizonte de intervenção como profissionais da área. Um dos trabalhos em que atuamos, no Complexo da Maré, realizou-se entre os anos de 2010 e 2013: Projeto de Educação Ambiental e Comunicação Social do Programa de Revitalização, Urbanização e Recuperação Ambiental dos Canais do Fundão e do Cunha (Secretaria Estadual de Meio Ambiente). Nossa atuação foi como parte da equipe de Coordenação Pedagógica do Curso de Formação de Monitores Socioambientais da Maré (Edumaré) ${ }^{1}$, um dos eixos da proposta mais ampla. A partir desse mergulho, desenvolvemos percepções outras sobre como se promovem as aprendizagens interculturais em espaços formais e não formais, incluindo as áreas de alta vulnerabilidade socioambiental, como as favelas pertencentes à região. Consideramos que nessa oportunidade foi possível ampliar nossas análises sobre processos contra-hegemônicos que envolvem os segmentos negros em situação de extrema exclusão social. No contato com realidades periféricas, percebemos uma tomada de posição de famílias atuantes frente aos problemas cotidianos, e esses grupos estão representados como não pertencentes ao espaço geográfico mais amplo - a cidade.

Para nosso estudo, tornou-se indispensável rever essas paisagens urbanas em que populações racializadas se deslocam com suas estratégias de reconhecimento das histórias das lutas engendradas. O território ocupado é aquele que sobrou na conformação da urbe e, nele, famílias negras e empobrecidas se refugiam e coexistem, enfrentando os códigos urbanos e as idiossincrasias geradas pela invenção da diferença. Racismo, segregação e invisibilidade fazem parte do mosaico dessa experiência excludente, sendo esse um dado central em nossa abordagem acerca das subjetividades assim marcadas. Entendemos que são afetações também coletivas e, ao mesmo tempo, que favorecem a criatividade e se desdobram em alternativas para a construção de memórias contra-hegemônicas, como é o caso do Museu da Maré. Tratase de uma proposta gestada em 2006, por um grupo de moradoras(es) e ex-moradoras(es) preocupadas(os) com as transformações estruturais da região. Para Araújo (2012, p. 78) “os museus comunitários no Brasil e no mundo procuram revisitar o processo criador de subjetivação e de construção de memória como resistência a uma nova ordem globalizada". No caso do Museu da Maré, os fatos históricos deixam evidente a luta das famílias pelo próprio chão (p.99), e esses esforços foram cartografados, resultando em parcerias significativas entre o Centro de Estudos e Ações Solidárias da Maré (Ceasm) e museólogos do Instituto do Patrimônio Histórico e Artísitico Nacional (Iphan). 
No ir e vir exigido pela pesquisa expedicionária ${ }^{2}$ que realizamos na América Latina, o contato com o Projeto Fundo Documental Afro-andino em Quito (Equador), impactou-nos ao ponto de desenvolvermos uma análise comparativa incluindo as pegadas de um esforço comunitário dos afro-equatorianos feito com o intuito de construir a memória afrodescendente em um país que conta com cerca de quase $15 \%$ de negros(as) e luta para reconhecer essa presença.

Em 1997, o Congresso Nacional institucionalizou o 'Dia Nacional do Negro' no Equador e tem sido levado a reconhecer sua história e seus processos de resistência em regiões como a Costa Pacífica e, por isso, a comprometer-se com políticas públicas para atender à demanda da Diáspora Africana. Defendemos outros "giros epistemológicos" e percepções sobre "lugares de memória" (NORA, 1993). Dessa vez, trabalhamos com uma noção de lugares de memórias contra-hegemônicas, já que as populações negras envolvidas nos processos escolhidos para análise estão em disputa com as propostas hegemônicas.

Sob influência do pensamento educacional latino-americano, valorizamos a perspectiva de colaboração adotada por Orlando Fals Borda (1925-2008), que, com o projeto "La Rosca" (1970), ${ }^{3}$ dinamizou um movimento interessado no processo sócio-político das populações presentes nesse conjunto de países. Como parte desse contexto, o Brasil tem muito a dizer a respeito do avanço das pesquisas sobre educação para as relações étnicoraciais e, para a análise sobre aprendizagens outras em espaços de construção de memórias negras, é importante insistirmos com análises comparativas. Consideramos o potencial colaborativo que anima a equipe do Projeto Fundo Documental Afro-andino, hoje localizado na Universidade Andina Simón Bolívar. Chamou nossa atenção as estratégias para preservar um acervo de mais de 30 anos de construção e ainda o fato de ter sido fomentado por intelectuais-pesquisadoras(es) das comunidades afro-equatorianas.

Escolhemos como método de investigação a análise comparativa, tendo em vista que esta abordagem visa contemplar estudos de casos e permitir a identificação de elementos constantes, similares e abstratos (LAKATOS; MARCONI, 2004). As propostas que escolhemos para realizar uma análise comparada apresentam contribuições de relevo sobre memórias contra-hegemônicas em contextos periféricos e, com esse olhar, gostaríamos de incrementar o campo temático perseguindo outros sentidos filosóficos, políticos e estéticos de educação para as relações étnico-raciais. Consideramos os lugares de memórias contrahegemônicas como espaços não formais de aprendizagens multidimensionais que inspiram pedagogias decoloniais. Isso se dá por não terem a intenção de "guardar" a memória, mas de construí-la em movimentos contínuos e intergeracionais. Nessa abordagem, não nos interessa 
a memória do poder (CHAGAS, 2000), e sim o poder da memória como instrumento de luta em prol do reconhecimento e da valorização das culturas dos estratos afetados pela degenerescência de suas identidades. Essa abordagem, que vai na contracorrente e desliza por outros territórios e outras concepções de poder, tem oferecido chaves decoloniais sobre processos mais politizados, ancorados em um ideário de maior justiça epistemológica.

As travessias são insurgentes e, no caso do Fundo Documental Afro-andino, um dos recursos adotados para defender a história e a presença da Diáspora Africana no país foi instituir parcerias com a Universidade Andina Simón Bolívar - instituição criada, entre outras demandas, para esse tipo de cooperação com os segmentos da região. A "Política de Etnoeducación Afro ecuatoriana" (2018) já pode ser estudada como fruto desses interstícios promovidos por várias mãos, numa perspectiva de colaboração intercultural.

No Brasil, outras influências devem ser apontadas, entre as quais o ideário da educação das relações étnico-raciais como legado do Movimento Negro Brasileiro. A práxis educativa e o mundo da vida se alinharam ao longo de mais de 50 anos de reivindicação de direitos socioeducacionais para mais de $50 \%$ da população do país, que se autodeclara negra. Inúmeras organizações e coletivos foram responsáveis pelo desenvolvimento de iniciativas de impacto, que desestabilizam positivamente o pensamento educacional nesse início do século XXI. Alinhadas aos estudos de Nilma Lino Gomes (2017), compreendemos que esses desdobramentos podem ser definidos como parte de um movimento negro e educador, tendo em vista a sua capilaridade em termos propositivos, inspirando, inclusive, os modelos de políticas educacionais nas duas experiências aqui em questão. Notadamente, ao investigarmos as principais influências epistemológicas implícitas nesses processos, também retóricos, encontramos ideias de ruptura, de descontinuidade, de reorientação e de inauguração de 'outras educações'. Entendemos, portanto, a existência de um processo de reorientação epistemológica, sendo esse um dos resultados do trabalho que aqui nos agrega. E essa opção é vigorosa, na medida em que nos coloca frente ao legado do pensamento pedagógico latinoamericano, do qual o Brasil é partícipe. Essa dimensão é identificada quando acessamos trabalhos ${ }^{4}$ produzidos por grupos de investigações que se dedicam a compreender a importância da educação para as relações étnico-raciais. Com essas interseções, localizamos a justificativa para promover estudos comparados incluindo países como o Brasil e o Equador.

Em toda a região definida como América Latina, sofremos de um apagamento garantido pela violência colonial multifacetada, que gerou lacunas incomensuráveis, além de facilitar a autorreferência dos grupos herdeiros das vantagens coloniais. Não obstante, esse fenômeno também pode ser relacionado com o estímulo à autodeterminação dos setores 
explorados, com a criação de saídas que implicaram organização social, econômica e política. Referimo-nos às outras formas de reexistir que atravessam o Brasil do século XXI e podem ser encontradas na experiência desses movimentos negros do Brasil e do Equador. Com práticas e dinâmicas transgressoras, comunidades negras rurais e urbanas realocam os sentidos atribuídos às diferentes culturas em disputa, fomentam a criatividade, apoiam a composição de outras ambiências e deixam como legado aprendizagens dissonantes. Com essas pegadas, são eles que nos orientam a considerar pedagogias decoloniais e perspectivas de insurgência comunitária.

Trabalhar pedagogicamente a partir da memória e da história das populações negras implica assumir a legitimidade de suas narrativas e memórias. Sob essa orientação, demos ênfase aos seus processos de re-existência e ressaltamos suas disputas territoriais, que podem ser identificadas como parte dos quilombos urbanos e rurais. Por outra parte, é justamente no interior da colonização que nasceram ideias revolucionárias garantindo o protagonismo dos diferentes outros inventados por um sistema de hierarquização. Em uma perspectiva menos unívoca e mais intercultural, é possível incluir as narrativas museológicas como constructos para 'outras educações'. Do mesmo modo, conceber processos de colaboração entre as comunidades e as universidades, por gerar ambiências de cooperação. A luta pela reexistência, no sentido apresentado por Adolfo Albán Achinte (2013), é o mote para localizarmos o temário aqui em questão. Os dados estatísticos sobre favelas no mundo indicam o avanço da pobreza urbana, e esse já é um dos mais graves problemas do século XXI. Em termos gerais, o que se vê é o agravamento da condição real de subsistência de um número sem tamanho de pessoas nas grandes metrópoles e nos contextos rurais, e esse quadro situacional demanda reflexão sobre as alternativas de politização das juventudes.

Conforme assinalam Elizabeth Castillo Guzmán e Jose Antonio Caicedo Ortíz (2010, p. 110), a história das outras educações pode ser lida à margem do fenômeno da educação para os outros, já que ambas "expressam planos e tensões que as determinam mutuamente e, portanto, requerem ser analisadas de forma dialética, no plano da simultaneidade que sirva para compreender sua coexistência na história social, política e cultural”. Nossa perspectiva investigativa está influenciada pela possibilidade de 'análises dialéticas no plano da simultaneidade' e interessamo-nos por abordagens que reconhecem a coexistência epistemológica quando o tema é, sobretudo, a história social, política e cultural das populações negras. Alinhadas a esse pressuposto, concebemos como viável outra práxis educativa, estando no centro de nosso argumento os processos de reorientação epistêmica para 
os currículos praticados em espaços não formais e em contextos ainda desconsiderados como produtores de conhecimentos.

Como professoras e pesquisadoras responsáveis por projetos de cooperação com docentes da educação básica, com vínculo no Ensino Superior, onde a escola é locus de aprendizagens interculturais, entendemos que são indispensáveis outras construções históricas de memórias coletivas. Os lugares de memória (NORA, 1993) podem ser espaços educativos não formais cujas aprendizagens sejam valoradas, tanto quanto o são as fomentadas nas instituições formais. Nesse sentido, é fundamental agregar a discussão sobre outras educações, conforme explicitam Guzmán e Ortiz (2010).

\section{Cartografias periféricas para a construção de referenciais epistemológicos outros}

“Lugares de memória” é uma definição adotada por Pierre Nora (1993) e se refere aos lugares em que se ancoram as memórias coletiva e individual reveladas em elementos materiais ou não materiais, como o sabor da comida, os ritmos musicais, os valores religiosos, entre outros aspectos. Com os estudos de Helena Maria Marques Araújo (2007, 2009, 2012, 2016), vimos que essa definição ganha importância crucial por concretizar, através do patrimônio material e não material, a busca de laços de pertencimento que geram o fortalecimento identitário. Ao pensarmos com Mario Chagas (2012), é preciso democratizar não só o acesso aos museus, mas a própria concepção de memória. Em outros termos, entra em debate o tema do acesso à memória, mas com novas perguntas sobre que memória(s) estamos legitimando.

Nesse percurso, aprendemos como a construção e a valorização dos lugares de memória contra-hegemônicas fortalecem identidades comunitárias, podendo ser parte das estratégias de luta para os movimentos sociais ou formas de cristalizar hierarquizações do poder local. O uso estratégico da memória coletiva é uma das dimensões ressaltadas por Walsh e Salazar (2015, p. 82) ao discutirem aspectos das práticas pedagógicas de existência afro-equatoriana. A memória coletiva é, assim, “filosofia e aprendizagem dos mais velhos como prática decolonial para recuperar, fortalecer, reposicionar e reconstruir a existência como direito ancestral". Como vimos em distintas partes da América Latina, no Equador, os povos afrodescendentes também foram ignorados pelo Estado. Notadamente, tal esfera aparece como parte do problema que afeta sobremaneira os segmentos desautorizados com a sua invisibilização, os quais negociam diferentes formas de pertença social. Ao pensar com Walsh e Salazar (2015, p. 83) aprendemos que “casa adentro, o Projeto Fundo Documental Afro-andino se desenvolve com o processo de escrever a memória coletiva como ferramenta 
para construir e fortalecer um sentido de pertencimento, compreensão e comprometimento entre as novas gerações distanciadas [...] da tradição oral”.

Podemos entender que cartografias decoloniais sugerem formas mais amplas de expressão das linguagens, dos saberes diversos que emergem tendo como objetivo a experiência coletiva e também a ruptura com a violência simbólica. Sem a pretensão de esgotar as inúmeras dimensões dessas distintas possibilidades - de localizarmos processos de ruptura e de resistência casa afuera -, entendemos como indispensável alinhar as iniciativas comunitárias das periferias com os processos que sugerem decolonialidade(s). A heterogeneidade histórico-estrutural mencionada por Aníbal Quijano (2005) tem sido um motor para a proposição de caminhos contra-hegemônicos nos contextos periféricos.

A memória é sempre uma construção, na qual a lembrança é parte constituinte da nossa identidade, do nosso sentimento de pertencimento. Já o conhecimento histórico traz a elaboração de arquiteturas de sentido que excedem os próprios recursos da memória coletiva através de processos de articulação entre acontecimentos, estruturas e conjunturas. A história pode ampliar, completar e até refutar o testemunho da memória sobre o passado, mas não pode aboli-lo. Beatriz Sarlo (2007) e Paul Ricoeur (2007) consideram história e memória duas áreas em conflito, tendo em vista que nem sempre a história credencia a memória, assim como a memória duvida da história, quando os direitos da lembrança não ganham centralidade. Sendo assim, fomenta-se uma ideologia de 'cura' identitária por meio da memória social ou pessoal. De certa forma, os lugares de memória que tomamos para análise tentam fazer esse ritual através do fortalecimento de comunidades excluídas do sistema socioeconômico vigente. Precisamos analisar o que garante à memória a primeira pessoa como condutora de um sentido de experiência social relacional e afetiva. Já a história é concebida como distante e inteligível (SARLO, 2007). Entretanto, nas últimas décadas, presenciamos uma aproximação entre a história e a memória, visto o crescimento da micro-história e das histórias orais.

Ricoeur (2007) menciona lembranças e esquecimentos - o que queremos lembrar e esquecer -, e todo o trabalho de memória envolve essa tensão com a história. São os esquecimentos que possibilitam a sua reescrita. Dialeticamente, são os esquecimentos e as ausências que permitem a renovação, a reinvenção, o dinamismo, a recriação da história e da própria memória. As memórias contra-hegemônicas nascem no movimento de coletivos interessados em apresentar referências da história local, de modo a permitir que seus moradores reflitam sobre essas questões e se envolvam nesse processo. Sendo assim, percebemos como a dimensão educativa se faz presente em todos os lugares de memória. Uma das questões cruciais em nosso estudo é o fato de que as memórias podem ser 
libertadoras ou dominadoras, e isso depende do uso que delas se faz. Os sujeitos dessas memórias são protagonistas de suas próprias reinvenções, que por sua vez refletem a representação do outro e indicam novas potencialidades. Tais memórias e saberes se perpetuam nas redes educativas do cotidiano, e construir memórias muitas vezes "esquecidas" pelas classes dominantes é um dever, uma necessidade jurídica, moral e política (SARLO, 2007). Portanto, entendemos que nossa análise pode colaborar para fomentar outras pesquisas em prol de novos vínculos com o pensamento decolonial.

Por outra parte, os movimentos populares são vanguarda, na medida em que ocupam, por exemplo, os territórios quilombolas com outras aprendizagens, desafiando as instituições do Estado e recriando formas de desaprendizagens, tão necessárias na atualidade. Portanto, com as pedagogias decoloniais, provocamos deslocamentos epistêmicos pela crítica nelas contidas. Movimentamo-nos rumo ao Sul e reconhecemos junções possíveis aproximando as realidades do Brasil e do Equador. Nessa Diáspora, estão alguns rastros decoloniais deixados nas experiências e nas memórias coletivas, facilmente reconhecidos na dinâmica de organização e reorientação epistemológica.

\section{Lugares de memória e outros tempos históricos}

Recuperar as alternativas de resistência para os segmentos que, às margens da cidade, reinventaram a cidade, pode significar a ampliação de outras fronteiras simbólicas. De certo, referimo-nos a processos de ruptura com estigmas e a concepções históricas na contracorrente. Partimos de algumas premissas e análises que nos permitem estabelecer vínculos inspirados em diálogos interculturais, privilegiando coletivos periféricos e, historicamente, subalternizados.

Para Adolfo Albán Achinte (2013), faz diferença considerarmos que o campo das práticas artísticas e visuais se converte em um território propício para a configuração de novas representações, que dinamizam outras experiências políticas. Esses aspectos estão presentes em contextos de tensões, ausências e silêncios, e a investigação que realiza inclui linguagens artísticas que alavancam procedimentos de investigação e influenciam as nossas análises sobre a concepção do Museu da Maré, bem como sobre os desdobramentos garantidos pelo Projeto Fundo Documental Afro-andino. Vimos como essas iniciativas se alinham com o que o autor destacou com movimentações que envolveram artistas afro-colombianos e indígenas:

O rastreamento da memória, as auto-representações [sic], a denúncia do racismo e todas as formas de discriminação, o reconhecimento do território, aspectos de ordem cosmogônica e práticas culturais da vida cotidiana se reuniram nesta mostra construindo com isso um referencial importante na 
medida que emergiram artistas e artefatos para dizer ao país que este está pintado de múltiplas cores e que a diversidade também é estética. (ALBÁN ACHINTE, 2013, p. 464).

Nessa medida, a pesquisa sobre memórias engendradas no Museu da Maré (Rio de Janeiro) e no Projeto Fundo Documental Afro-andino (Quito) nos colocam lado a lado com os estudos que influenciaram o campo de teorização e de práxis social do qual somos partícipes: as pedagogias decoloniais. Com suas agendas interventivas, identificamos outras aprendizagens, que oferecem leques interpretativos acerca dos sentidos possíveis ao trabalho de construção de memórias ancestrais para as populações negras. Sob essa orientação, identificamos ainda a dimensão etnoeducativa de suas propostas, a partir da construção e da ressignificação das histórias locais e das estratégias de pertencimento social.

\section{O Museu da Maré e o Fundo Documental Afro-andino}

Os museus de favela, no Brasil, surgem em um momento de maior democratização da luta social e política (a partir da década de 1980) em prol dos direitos básicos do cidadão. São criados na esteira das reivindicações populares, alcançando visibilidade para o protagonismo comunitário. Na análise de Ricoeur (2007), a busca de uma "memória feliz" é a construção de uma memória justa, ou seja: que insiste em se fazer presente na "contramão" da história oficial, valorizando lutas e processos de resistência de comunidades subalternizadas em prol não só de sua sobrevivência mas também do exercício de uma postura crítica. As histórias e memórias locais construídas através de objetos, paisagens, músicas, comidas, dentre outros artefatos, são como as 'palavras geradoras' de Paulo Freire, promovendo lembranças e sentimentos de busca de si e do outro. Assim sendo, nessas memórias contra hegemônicas entrosam-se identidades e alteridades, num jogo contínuo e transformador de subjetividades. As peças reunidas, os móveis, os utensílios domésticos e adornos diversos fazem parte da reinvenção da vida e de memórias clandestinizadas. ${ }^{5}$ De certo, estamos todos situados e falando de algum lugar. Quem não fala não existe, não decide, não participa, não está representado. Contar suas próprias histórias: essa tem sido uma das tarefas dos 'outros' inventados nos discursos coloniais.

O Museu da Maré tem uma história singular e é assim analisado por estar ancorado na luta por moradia, por isso se converte em uma agenda comunitária. Seu espaço físico é o Morro do Timbau, mais precisamente a Rua Guilherme Maxwell, número 26, Bairro Maré. Foi criado em 2006 e inaugurado pelo então Ministro da Cultura Gilberto Gil. Ganhou expressão por ser o primeiro museu situado em uma favela, mas, sobretudo, por ser idealizado pelos próprios moradores, entendidos aqui como agentes sociais atuantes em prol das 
melhorias de suas vidas. Como um espaço de aprendizagens outras, reproduz em doze ‘tempos' (água, casa, migração, resistência, trabalho, festa, feira, fé, cotidiano, criança, medo e futuro) percepções diacrônicas e sincrônicas, e sua organização está conformada por tempos 'cíclicos' e 'temáticos', que ressignificam o tempo cronológico, além de contemplarem as etapas das lutas e conquistas das populações que representam. Grupos familiares envolvidos no propósito de construção de suas moradias desenvolvem uma tecnologia para construir as suas memórias, e esse é um aspecto-chave, porque, mesmo sem o apoio estatal, imprimem um modelo imprescindível de geração de significados da existência comunitária. Em todo o globo, mais de um bilhão de pessoas vivem em favelas, e a parte Sul do mundo apresenta a maior concentração, conforme dados mais recentes (DAVIS, 2006). Andrelino Campos (2010, p. 161) afirma que "assistiu-se à transmutação do espaço quilombola em favela após a Abolição. As favelas [...] passaram a ser combatidas pela necessidade do Estado regulamentar o uso do solo na cidade, associada aos interesses da classe dominante".

Ao dar centralidade às marcas da trajetória coletiva de segmentos que se reinventam em agendas coletivas, entendemos esses caminhos e descaminhos como um processo que exige desaprendizagem, seguindo as proposições de Juan García Salazar (2011), porque com ele entendemos a importância de subvertermos os valores impostos por uma história oficial, e a saída é aprender de nós mesmos a partir da memória ancestral. De certo, reviver/reconstruir essas memórias tendo como base a filosofia casa adentro e casa afuera implica assumir perspectivas que fazem menção a 'outras epistemologias'.

Destacamos que nas memórias da Maré estão as marcas da violência territorial e as fissuras provocadas pela degenerescência dessas identidades periféricas. Esses efeitos foram perceptíveis quando trabalhamos com os(as) jovens dessas famílias. São importantes dimensões para compreendermos a importância de aproximarmos esses campos de teorização - relações étnico-raciais, memórias e espaços não formais de educação. Os resultados alcançados estão atravessados por esses lugares de memória, que pudemos identificar quando cartografamos processos de concepção desse ideário.

Também acreditamos que esse espaço é educativo e fruto de estratégias de associativismo e de alianças realizadas em um contexto de vida e de morte, enfrentado por populações postas à margem das estruturas mais sólidas. Elas atravessaram todo o século XX disputando sentidos de existência em uma dinâmica de recomposição sócio-histórica. Com os seus registros imagéticos, ficam explícitos os modos de fazer da(s) memória(s), uma peça indispensável na luta social e política. A autoria dessa construção se dá nos caminhos percorridos com dificuldades e dor, exige desaprendizagens das histórias oficiais a partir de 
outros constructos epistemológicos explícitos. Não aqueles que revelam marcas coloniais, mas sim os que estão ancorados em saberes que favorecem experiências de recomposição curricular.

Com a intenção de promover ações articuladas que possam envolver diferentes instâncias (formais e não formais) - e por acreditarmos em uma perspectiva menos unívoca e mais intercultural -, compreendemos as narrativas museológicas comunitárias como um aspecto central para 'outras educações' e, com essa opção, outros programas de estudo podem ser elaborados.

O Projeto Fundo Documental Afro-andino pode ser analisado como uma iniciativa intercultural alinhada ao projeto do Museu da Maré, já que apresenta uma dinâmica organizacional em que lideranças comunitárias, coletivos de estudantes e intelectuais-ativistas da Universidade Andina Simón Bolívar estão empenhados na sua promoção. Entre as diferentes tarefas estão: digitalizar, classificar e catalogar uma série de materiais visuais, orais, audiovisuais e impressos sobre o Equador e a região andina. Hoje, é o maior repositório de materiais orais, visuais e escritos sobre as populações afro-andinas do país e possui coleções que facilitam o acesso a esse acervo: coleção de áudio (3 mil horas de gravação), coleção fotográfica (10 mil fotografias desde a década de 1990), coleção audiovisual (materiais audiovisuais e produções audiovisuais) e coleção escrita, digital e impressa (documentos históricos, contemporâneos e textos publicados).

O Fundo Documental Afro-andino é uma importante referência de luta e de reexistência das populações afro-equatorianas e foi criado em 2002 como resultado da parceria entre o Processo de Comunidades Negras (iniciativa de mobilização negra local) e a Universidade Andina Simón Bolívar (Quito). Podemos defini-lo como um Centro Arquivístico com um trabalho mobilizador de preservar um acervo fotográfico e a coleção de fitas com conteúdos da história oral. O trabalho foi organizado por uma equipe de afroequatorianos situada nas comunidades de Esmeraldas e no Valle do Chota, ao longo de mais de 30 anos de intervenção social. O objetivo mais amplo dessa conformação comunitária, a nosso ver, é multidimensional e inclui preservar e possibilitar o uso do acervo para diferentes demandas.

Outro objetivo de destaque é a recuperação de materiais de investigação dos testemunhos orais e documentos imagéticos sobre os(as) afro-equatorianos(as) visando gerar espaços de discussão por meio de fóruns, mesas redondas e oficinas de intercâmbio. O ideário de construção dessa memória se reflete nos modos de concepção do trabalho, e a retroalimentação é uma exigência dos movimentos em prol da valorização de culturas 
silenciadas historicamente na Região Andina. Com esse compromisso, seus(suas) responsáveis desenvolvem atividades e produções diversas, com destaque para materiais didáticos no formato de multimídias abarcando saberes próprios, religiosidade e lutas pelo reconhecimento da presença afro-equatoriana. Dentre as publicações do Fundo está Papá Rincón: história de vida (2011), organizada por Juan García Salazar (2011), um dinamizador estratégico nessa ação colaborativa. Salazar (2011, p. 9) reconhece a importante dinâmica de apoio mútuo que marca esse registro que saiu por Ediciones Abya Yala:

Um dos objetivos principais dessa história de vida é, sem dúvida, o de ressaltar o profundo e forte sentido de pertencimento de Guillermo Ayoví, "Papá Ricón", às origens africanas, mas também de mostrar a obediência consciente desse guardião da tradição aos mandatos ancestrais do povo afroequatoriano.

Nessa sistematização alcançada coletivamente, a defesa que mobiliza Salazar é de fomentar um espaço comunitário para aprendizagens casa adentro. Poderíamos dizer que a história oral preservada pelo projeto sustenta desaprendizagens sobre a(s) história(s), a(s) cultura(s) e o(s) conhecimento(s) ensinados pelos sistemas educacionais, que pouco consideraram a pluridiversidade que nos caracteriza como sociedades híbridas no âmbito da América Latina. Do mesmo modo, os artistas e suas intervenções cotidianas retroalimentam as outras aprendizagens silenciadas nos currículos praticados.

O trabalho da coreógrafa afro-equatoriana Luzmila Bolaños, por exemplo, é de extrema relevância para a construção dessa memória negra. As garrafas usadas na cabeça, os lenços, os turbantes, os vestidos e as saias afro-equatorianas não aparecem apenas como artefatos. Ao contrário, são peças reveladoras dos significados de uma construção histórica e dão novos sentidos às oficinas dinamizadas pela artista. Fazem parte da metodologia de trabalho para compreender as representações de um segmento social em luta permanente por sua existência. A Bomba de Chota passa a ser localizada para além de 'uma expressão corporal' e emerge como parte de um modus operandi anticolonial, por carregar nuances da pertença afro-equatoriana. $\mathrm{Na}$ análise desenvolvida por Catherine Walsh e Juan García Salazar (2015) sobre memória coletiva e seus usos, os autores afirmam que a tradição oral tem sua base histórica e se relaciona com experiências práticas e pedagogias de pensar, sentir, ser e estar dos povos de origem africana do Equador. Nesse caminho, entendem que "o território é o lugar onde se assentou a memória e a existência dos povos de origem africana como mecanismos de vida". Complementam afirmando que, "tomados juntos, o território, a memória e a existência são práticas decoloniais que seguem não apenas resistindo e indo contra a ordem estatal, mas construindo e criando modos outros de ser, saber e fazer apesar do Estado" (WALSH; SALAZAR, 2015, p. 96). 
Se assim os pudermos considerar, os lugares de memória são marcados pela insurgência de suas populações e por diferentes modos de interrupção das degenerescências forjadas na aventura colonial e escravocrata. As estratégias de insurreição podem ser aproximadas mesmo estando em diferentes países, e nas investigações em que compartilham seus modos de conceber a interculturalidade, Walsh e Salazar (2015) destacaram aspectos sobre como a afroexistência foi moldada, significada e construída, mesmo sem o apoio do Estado. Nas favelas do Complexo da Maré, o que se vê são estratégias e tecnologias de sobrevivência, além de uma história coletiva de luta pelo direito à moradia. Ocupar o espaço geográfico da região e enfrentar os doze tempos acentuados nos registros apresentados na exposição permanente do Museu são algumas das marcas das práticas anticoloniais e de reação ao fenômeno de invisibilidade de sua pertença social. Conforme os autores, "a existência se construiu nas margens, pontos cegos e 'terras baldias' que existem fora dos próprios marcos de reconhecimento, dos direitos e da cidadania constitutivos do Estado" (WALSH; SALAZAR, 2015, p. 81). É com base na essência dos processos anteriores que construímos a problemática da memória, sob as formas de existir e de reexistir, numa perspectiva contra-hegemônica, bem como as outras educações sugeridas e dinamizadas em espaços não formais.

As interseções que localizamos incluem um território de amplas possibilidades epistêmicas e, nessa arena propositiva, vislumbra-se interfaces que abrigam os conceitos de memórias (SARLO, 2007; RICOEUR, 2007) e as pedagogias decoloniais (WALSH, 2013; MIRANDA, 2013). No sentido a ela dado por Guzmán e Ortiz (2010, p. 124), “a história das outras educações é também a história social de resistências e submissões no marco temporal e espacial concreto no qual se confrontam modelos de subalternização epistêmica, agora através de estratégias educadoras que se autodefinem emancipatórias". Cartografias decoloniais provocam mudanças de status de narrativas e de protagonistas historicamente representados como ‘fora do lugar' e, portanto, subjetividades desautorizadas. Walsh e Salazar (2015, p. 97) sugerem "uma ética e uma prática de tipo decolonial, que em vez de (re)ordenar a memória coletiva para adaptar-se às estruturas da literatura e da escritura, alteram e transformam o que se conhece como literatura e escritura e sua relação com a tradição oral”. Entendem os aurores que esse desafio se apresenta também em outras partes da diáspora afro-latino-americana.

Sobre a experiência do Brasil, importa dar ênfase aos desafios enfrentados pelos segmentos negros, por conta do fenômeno do racismo e da sua fixação como subalternizados. Em pesquisa sobre planejamento urbano, Andrelino Campos (2006, p. 302) aponta para a invisibilidade dos afrodescendentes: 


\begin{abstract}
A maneira pela qual se fomentou uma ideologia segregacionista passou pela difusão dos valores negativos atribuídos aos lugares de moradias de negros e outros elementos que compunham os grupos de menor expressão social. Os guetos e os lugares que concentravam as minorias eram considerados patológicos responsáveis pela degradação humana, e mereciam ser evitados por brancos. Além de considerados ambientes insalubres, portanto a serem evitados, os agentes imobiliários os associaram também ao subdesenvolvimento cultural, atribuindo como fator de atraso o modo pelos quais os negros viviam em suas práticas espaciais cotidianas. Então, a degradação ambiental, a cultura atrasada, a violência são elementos que vêm, pelo menos, desde 1900 sendo potencializados na constituição de uma vizinhança que se pretenda "saudável".
\end{abstract}

Essas representações sociais se revelam no cotidiano e fazem parte de um modelo que alimentou a ideia de inferioridade desses contextos. Através de tais mecanismos, as populações das favelas foram deixadas à margem e, de alguma forma, tiveram que aprender a reexistir. As peças que compõem parte do acervo do Museu da Maré evidenciam estratégias de reinvenção das identidades locais e, consequentemente, as marcas da sua reinvenção. A humanidade reconstruída é um processo pedagógico que se apresenta coletivamente e surpreende grupos que não fazem parte dessa história de resistência. A Lei de Terras (1850), no Brasil, impedia a aquisição de propriedade por parte dos negros, e tal manobra oligárquica garantiu a condição de um tipo de esgotamento das condições sociais dessas populações clandestinizadas. Quando examinamos as narrativas dos museus hegemônicos, observamos um apelo ao sistema colonial clássico, um tipo de inspiração que assegura, a partir de uma reconstrução constante da memória, práticas de subalternização dos 'outros da colonização', os que foram fixados como 'diferentes' e excluídos do modelo de humanidade.

$\mathrm{Na}$ contramão desse legado e, dando pistas de insurgência, os estratos sociais postos à margem experimentam rupturas estratégicas. Tudo isso implica escrever às avessas, imprimindo outros discursos, como aqueles reunidos e transformados em acervo no Projeto Fundo Documental Afro-andino. Tudo isso é parte de um itinerário a ser realizado também pedagogicamente. A nosso ver, são urgências pedagógicas pelo lugar de importância de movimentos comunitários que disputam epistemologias e sugerem possibilidades e dinâmicas indispensáveis à crítica ao conhecimento produzido sobre as populações negras na Diáspora Africana. Essa concepção nos influencia no entendimento do que têm sido a representação do conhecimento produzido à margem. A partir de rupturas epistemológicas, podemos construir outras representações sobre os 'condenados da Terra', no sentido dado por Frantz Omar Fanon (1925-1961). Iván Pabón, em sua pesquisa intitulada Identidad afro: processos de construcción en las comunidades negras de la Cuenca Chota-Mira (2007, p. 114), entende 
que "devemos conhecer mais de nós mesmos para equilibrar com o que nos é ensinado dos 'outros', e é nessa direção que vai a Etnoeducação". O autor enfatiza seguinte:

Penso que a Etnoeducação, partindo do que nos é próprio, nos permitirá olhar outras formas de sair da marginalização e atenuar esta corrupção produto da educação oficial minimizada cada vez mais em valores, produto também das progressivas consolidações de estrutura globalizantes, desde a ótica cêntrica da cultura dominante. Nesse contexto, a Etnoeducação se localiza dentro dos esforços dos afro-equatorianos por definir e construir um projeto de sociedade e de vida de acordo com seus critérios, aspirações e a diversidade étnica do país. (PABÓN, 2007, p.105).

Equador tem uma dívida para com a suas populações afrodescendentes, e somente nessa segunda década do século XXI o tema da educação para as relações étnico-raciais (Etnoeducação) ganhou espaço como urgência educacional e curricular. No dia 11 de maio de 2018, o Ministério da Educação apresentou a "Política de Etnoeducación Afro equatoriana no Sistema Nacional de Educação", orientada ao fortalecimento de suas culturas a partir de uma metodologia que valoriza saberes próprios dos(as) afro-equatorianos(as). Um dado que justifica a elaboração e execução de uma política curricular dessa monta está relacionado ao modo de violação de segmentos africanos sequestrados para a região e ainda à estratégia adotada, semelhante à do Brasil, que implicou deixar os chamados 'libertos' sem terras e sem condições estruturais para seu provimento e de suas respectivas famílias. No século XVIII, a vinda de africanas e africanos se concentrou, em grande parte, no Valle del Chota, e existe uma lacuna em termos do reconhecimento desse vínculo. Os(as) afro-equatorianos(as) estão em processo de reinvindicação de suas identidades africanas, e a Etnoeducação é uma chave decolonial, conforme nossa análise sobre esse processo em curso.

A 'Política de Etnoeducación' inclui materiais pedagógicos organizados em cooperação com os representantes das comunidades afro-equatorianas, e essas diferentes participações legitimam o processo de concepção da proposta educacional. Seguramente, as demandas apresentadas pela Etnoeducação afro-equatoriana ganharam relevo: "Etnoeducación es el proceso de enseñar y aprender casa adentro para fortalecer lo propio del que nos hablan los ancestros" (SALAZAR, 2003, p.14). Corresponde à educação para as relações étnico-raciais quando aproximamos as experiências do Equador e do Brasil, na luta pela implementação das diretrizes para um currículo mais justo.

Por ocasião da entrega da política de Etnoeducação Afro-equatoriana, a pedagoga María Luisa Hurtado, uma das representantes de Etnoeducación, declarou: “a Etnoeducação permite que a cultura ancestral seja transmitida a todos os equatorianos; é a ferramenta pedagógica que nos permite descobrir o conhecimento ancestral”. As populações afro-andinas 
são populações que reivindicam reconhecimento de sua presença e não aceitam as estratégias de fixação de identidade como aquelas em que são reconhecidas por 'cantar' e 'dançar' o baile da Marimba. Suas reivindicações giram em torno dos aportes históricos e culturais próprios de suas ancestralidades africanas.

\section{Para concluir}

As cosmovisões de comunidades da Diáspora Africana nos revelam algumas brechas e atalhos que nos ajudam a entender a pluralidade, os ecossistemas e a coexistência. São essas populações que organizam práticas sociais e culturais e apresentam dinâmicas outras em confronto com o status quo. São esses coletivos populacionais à margem, em diferentes países da região da América Latina, capazes de promover ancoragens díspares para reorganizar a transposição cultural em espaços de educação formal e não formal.

A problemática apresentada neste trabalho é parte de algumas inquietações teóricas e epistemológicas relacionadas à práxis social e aos movimentos populares que vimos de perto nas pesquisas desenvolvidas com sujeitos coletivos. Buscou-se, com eles e elas, outras educações e outras aprendizagens sobre a cidade, a transposição cultural e as memórias coletivas. Destacaram-se interfaces que têm a ver com a vitalidade do pensamento decolonial e as correlações com os espaços educativos não formais. Os lugares de memória localizados nas periferias indicam atalhos importantes e interseções urgentes, tendo em vista a dinâmica e a experiência cotidiana de populações presentes nas esferas educacionais nesses contextos. Pautamos nosso foco nas memórias contra-hegemônicas, tomando os lugares de memória como locus de formação e de reorientação epistemológica.

Ganhou relevo a força dos movimentos sociais, já que permitem que estabeleçamos vínculos com suas estratégias de enfrentamento, em que os saberes e os conhecimentos populares ganham maior importância. Memórias outras, ou seja, memórias contrahegemônicas foram consideradas aqui como marcos referenciais nos territórios populares que visibilizam memórias subterrâneas, conforme a visão de Pollack (1989). Com elas, é possível cartografar traços culturais, lutas de trabalhadores por terra, trabalho, melhores condições de vida e qualidade de sobrevivência. Essas noções de pertencimento a um grupo social são importantes para a construção de identidades coletivas e para a reinvenção das sociedades. De certo, cartografar dinâmicas insurgentes nos fez assumir um leque de possibilidades em termos de outras práticas pedagógicas. As lições mencionadas inicialmente, sob a perspectiva da educação em espaços de vulnerabilidade social extrema e outras movimentações pedagógicas de grande envergadura, serviram para nossa compreensão acerca de outros 
processos possíveis de desaprender e reconhecer as nossas inúmeras lacunas históricas. Os lugares de memória como o Museu da Maré e o Fundo Documental Afro-andino são possibilidades de descaminhos epistemológicos e de pedagogias decoloniais.

\section{Notas}

${ }^{1} \mathrm{O}$ projeto Edumaré objetivou promover através da Educação Ambiental Crítica, o empoderamento identitário de grupos em maior vulnerabilidade socioeconômica no território. A metodologia adotada foi a utilização de oficinas pedagógicas de expressão artística e de educação ambiental através das linguagens das artes plásticas, música, teatro etc.

${ }^{2}$ Sobre isso, consultar Claudia Miranda (2017).

${ }^{3}$ A partir da Fundação "La Rosca" e, juntamente com uma equipe de interlocutores/as, Orlando Fals Borda desenvolveu, nos anos de 1970, o método de investigação ação participativa com o foco nas questões socioculturais da América Latina vislumbrando promover a consciência social para transformar a realidade favorecendo as urgências das populações mais vulneráveis.

${ }^{4}$ Recomendamos o acervo do Grupo de Trabalho "21" - Educação e Relações Étnico - Raciais - da ANPEd (Associação Nacional de Pós-graduação e Pesquisa em Educação) disponível em seu portal: http://www.anped.org.br/.

${ }^{5}$ Sobre isso recomendamos o trabalho de Santiago Arboleda Quiñonez (2016).

\section{Referências}

ABREU, Regina; CHAGAS, Mário (org.). Memória e patrimônio: ensaios contemporâneos. Rio de Janeiro: DP\&A, 2003.

ACHINTE, Adolfo Albán. Pedagogías de la re-existencia. Artistas indígenas y afrocolombianos. In: WALSH, Catherine. Pedagogías Decoloniais: practicas insurgentes de resistir, (re) existir y (re) vivir. Quito: Ediciones Abya-Yala, 2013.

ARAÚJO, Helena Maria Marques. Memória e museus: construindo identidades. In: ANDRADE, Marcelo (org.). A diferença que desafia a escola: a prática pedagógica e a pesquisa intercultural. Rio de Janeiro: Quartet, 2009.

ARAÚJO, Helena Maria Marques. Museu da Maré: entre educação, memórias e identidades. 2012. Tese (Doutorado em Educação) - Pontifícia Universidade Católica do Rio de Janeiro, Rio de Janeiro, 2012.

ARAÚJO, Helena Maria Marques. Nos "lugares de memória" também se educa! MATTOS, Carmen Lúcia Guimarães de; BORGES, Luis Paulo Cruz; CASTRO, Paula Almeida de (org.). Didática e avaliação: educação, cidadania e exclusão na contemporaneidade. Campina Grande: Realize, 2016. Anais do IV Colóquio Internacional Educação, Cidadania E Exclusão: Didática E Avaliação.

CAMPOS, Andrelino. Do Quilombo à favela: a produção do espaço criminalizado no Rio de Janeiro. 3. ed. Rio de Janeiro: Bertrand Brasil, 2010.

CAMPOS, Andrelino. O planejamento urbano e a "invisibilidade" dos afrodescendentes: discriminação étnico-racial, intervenção estatal e segregação socioespacial na cidade do Rio de Janeiro. 2006. Tese (Doutorado em Geografia) - Universidade de Federal do Rio de Janeiro, Rio de Janeiro, 2006. 
CHAGAS, Mário de Souza. Memória e poder: contribuição para a teoria e a prática nos ecomuseus. In: Site:www.quarteirao.com.br/pdf/mchagas. 2000.

CHAGAS, Mário de Souza. Memória e poder: dois movimentos. Cadernos de Sociomuseologia, [S. l.], n. 19, v.19, p. 33-67, jun. 2002. Disponível em: https://bit.ly/2JzyVC6. Acesso em: 20 nov. 2018.

CHAGAS, Mário de Souza. Museu, Memórias e Movimentos sociais. Museus Agentes de Mudança Social e Desenvolvimento, $[S . l$.$] , n. 41, p. 5-16, fev. 2012. ISSN 1646-3714. Disponível em:$ https://bit.ly/2Hpa5Cr. Acesso em: 13 maio 2019.

DAVIS, Mike. Planeta favela. São Paulo: Boitempo, 2006.

GOMES, Nilma Lino. O movimento Negro Educador: saberes construídos nas lutas por emancipação. Petrópolis, RJ: Editora Vozes, 2017.

GUZMÁN, Elizabeth Castillo; ORTIZ, Caicedo José Antonio. Las luchas por otras educaciones en el bicentenario: de la iglesia-docente a las educaciones étnicas. Nómadas, [S. l.], n. 33, p. 109-127, out. 2010. ISSN 0121-7550. Disponível em: https://bit.ly/2E6UaYC. Acesso em: 20 nov. 2018.

LAKATOS, Eva Maria; MARCONI, Marina de Andrade. Metodologia científica. 4.ed. São Paulo: Atlas, 2004.

MIRANDA, Claudia. Apresentação. In: WALSH, Catherine (org.). Pedagogías Decoloniais: practicas insurgentes de resistir, (re) existir y (re) vivir. Quito: Ediciones Abya-Yala, 2013.

MIRANDA, Claudia. Clandestinización y re-existencia diaspórica: horizontes expedicionario e insurgencia en Afroamérica. In: SEPTIEN, Rosa C.; BIDASECA, Karina. (org.). Más allá del decenio de los pueblos afrodescendientes. Buenos Aires: Conselho Latinoamericano de Ciências Sociais, 2017. v. 1, p. 173-184.

NORA, Pierre. Entre memória e história: a problemática dos lugares. Projeto História, São Paulo, n. 10, p. 7-28, dez. 1993.

PABÓN, Iván. Identidad afro: procesos de construcción en las comunidades negras de la Cuenca Chota-Mira. Quito: Editorial Abya Yala, 2007.

POLLACK, Michel. Memória, esquecimento e silêncio. Estudos Históricos, Rio de Janeiro, v. 2, n. 3, p. 3-15, 1989.

QUIJANO, Aníbal. Dom Quixote e os moinhos de vento na América Latina. Estud. Av., [S. l.], v. 19, n. 55, p. 9-31, dez. 2005.

QUIÑONEZ, Santiago Arboleda. Le han florecido nuevas estrellas al cielo: suficiencias íntimas y clandestinización del pensamiento afrocolombiano. Cali: Poemia sua casa editorial, 2016.

RICOEUR, Paul. A memória, a história, o esquecimento. Campinas, SP: Editora da UNICAMP, 2007.

SALAZAR, Juan García. La tradición oral: una herramienta para la etnoeducación. Una propuesta de las comunidades de origen afroamericano para aprender casa adentro. Quito: FEDOCA-SL, 1983.

SALAZAR, Juan García. Papa Rincón: história de vida. Quito: Ediciones Abya Yala, 2011. 
SARLO, Beatriz. Tempo passado: cultura da memória e guinada subjetiva. São Paulo: Companhia das Letras; Belo Horizonte: UFMG, 2007.

WALSH Catherine; SALAZAR, Juan García. Memoria colectiva, escritura y Estado. Prácticas pedagógicas de existencia afroecuatoriana. Cuadernos de literatura, [S. l.], v. XIX, n. 38, p. 79-98, jul./dez. 2015. Disponível em: https://bit.ly/2VCGjUL. Acesso em: 20 dez. 2018.

WALSH, Catherine (org.). Pedagogías Decoloniais: practicas insurgentes de resistir, (re) existir y (re) vivir. Quito: Ediciones Abya-Yala, 2013. 